\title{
The Indoor Environmental Index and Its Relationship with Symptoms of Office Building Occupants
}

\author{
Demetrios J. Moschandreas \\ Department of Chemical and Environmental Engineering, Illinois Institute of Technology, Chicago, IL
}

Sait C. Sofuoglu

Department of Chemical Engineering, Izmir Institute of Technology, Turkey

\begin{abstract}
An index for indoor environmental quality, the Indoor Environmental Index (IEI), was developed. This study aggregates the Indoor Air Pollution Index, an index found in the literature, and a new index: the Indoor Discomfort Index. The average of these two indices is the IEI, which is calculated using concentrations of eight pollutants and two comfort variables measured in 100 office buildings in the United States. The database used was developed for the U.S. Environmental Protection Agency Building Assessment Survey Evaluation study. A symptom index also is developed to denote persistent occupant symptoms. The IEI and the symptom index are used to investigate the relationship between indoor environmental quality and symptoms. Two simple linear regression models were formulated; these models explain 67 and $79 \%$ of the variation in the average symptom index, with the variation of the average IEI depending on the method of averaging used in the construction of the models. In addition, a conceptual explanation is provided for the empirical or regression models formulated. The IEI and the associated models relating indoor environmental quality with the office occupant symptom index may be used as management tools, as illustrated with an example.
\end{abstract}

\section{IMPLICATIONS}

The IEI is a measure of indoor environmental quality in office buildings. This index can be understood easily by all concerned parties, including the occupants and the building managers; it associates well with an index of occupant symptoms; and it can be used as an indoor air management tool. Importantly, the index can be estimated promptly simply by conducting an occupant symptom survey and employing the model provided in this paper, thus avoiding the expensive and laborious measurement of environmental and comfort variables. To avoid false positive or false negative associations, a conceptual model is discussed as a management tool to determine whether indoor environmental quality intervention is required.

\section{INTRODUCTION}

Several recent efforts ${ }^{1-4}$ have focused on the need to formulate a measure of indoor air pollution. Such a metric is distinct from a measure of several individual indoor pollutants and must be understood easily and associated with symptoms of those exposed to indoor air pollution. The focus of this research is to formulate a new metric or an index for indoor quality. The driving force for establishing such a metric has three components: (1) complexity of the issue and the related communication discord among involved parties, namely, investigators of indoor environmental quality, building occupants, building managers, and regulators; (2) occupant symptoms are difficult to attribute to a single agent because the levels of such factors are usually low; and (3) efficient management of indoor environmental quality. Therefore, metrics of environmental quality must satisfy three requirements. First, metrics must be understood easily by all involved in assessing the environment, including the consumer, the potential polluter, the scientist, and the regulator. Second, metrics must associate well with measurements of the impact caused by the contamination ranked by the metric. Third, metrics must enable those concerned to manage the environment efficiently. Comments by Molhave, ${ }^{5}$ Wolkoff, ${ }^{6}$ and Moschandreas and Sofuoglu ${ }^{7}$ provide additional insights on the concerns, advantages, and limitations and, in general, the role of such measures in indoor environments.

Environmental quality indices do not constitute a new tool of inquiry. Indices have been developed and used for ambient air ${ }^{8-21}$ and water quality. ${ }^{19,22-27}$ Indices are considered suitable tools to assess the effectiveness of environmental policies in the context of sustainable development. ${ }^{28}$ However, such efforts are limited and relatively novel for indoor environments. A total volatile organic compounds (TVOC) level/index ${ }^{29}$ was proposed for consideration as an exposure indicator and indicator of effects. However, several questions have been posed by members of the indoor air scientific community who recognize that the TVOC 
indicator is limited in its predictive ability of health effects. ${ }^{6}$ The report ${ }^{30}$ from a Nordic consensus meeting in 1996 concludes that the scientific literature is inconclusive with respect to the relevance of TVOC as a risk index for health and discomfort effects in nonindustrial buildings and that its use for these purposes cannot be recommended; however, there is a need for new indicators. Jokl ${ }^{3}$ considers the numerical range of TVOC concentrations ${ }^{31}$ as "large" to develop claims that perception of odors is like that of noise and proposes "decitvoc" and "decicarbdiox" as new units for evaluation of IAQ. These units were developed in response to critiques ${ }^{32,33}$ of "olf" and "decipol" units" 34,35 that were proposed and accepted as the recommended method for assessing indoor air quality by the European Union. ${ }^{36}$ These methods (units) and more ${ }^{3,37}$ are based on perception. Perception-based indices are widely used in Europe; however, they have theoretical and statistical limitations. ${ }^{38}$

There are only three composite indices developed for indoor air: The Indoor Air Pollution Index (IAPI), ${ }^{1}$ the Indoor Pollutant Standard Index (IPSI), ${ }^{2}$ and the Index of Air Quality (IAQ). ${ }^{4}$ IPSI was developed to be an aggregate representative of the overall acceptability of indoor air quality. IPSI was modified from PSI, ${ }^{18,39}$ which was developed to be the nationally accepted uniform index for ambient air. The maximum operator is used as the aggregation function. A major disadvantage of this index is that the maximum operator ignores all pollutants other than the one with the maximum sub-index. ${ }^{20}$ Therefore, most of the information is lost during the aggregation, and the index fails to provide a measure for indoor air as an aggregate. Also, this index can take the same value in different buildings, but the concentrations of contaminants may not be the same. Thus, the index is not suitable for comparing the IAQ of different buildings. Furthermore, IPSI does not correlate with occupant symptoms. ${ }^{2}$ The other index, the IAQ, was developed for a software of energy management in buildings. The index is based on the ratio of exposure and threshold. It is not capable of rating IAQ on aggregate and, hence, has not found a wide use, and its association with occupant health symptoms was not studied.

The IAPI ${ }^{1,40,41}$ is a composite index; sub-indices are aggregated using the arithmetic mean in conjunction with a tree-structured calculation scheme. The IAPI was developed and validated using the U.S. Environmental Protection Agency's (EPA) Building Assessment Survey and Evaluation (BASE) database, ${ }^{42}$ which comprises air quality and occupant symptom information from 100 office buildings in the United States. The IAPI denotes the air pollution level of an office building with a unitless single number, the index. The index value ranges between 0 (lowest pollution level, best indoor air quality) and 10 (highest pollution level, worst indoor air quality). The index value is estimated using (1) the range of pollutant concentrations found in the U.S. office building stock, (2) a demarcation concentration (a standard or guideline value), and (3) concentrations measured in the subject building. The index value is easy to communicate to all in-office stakeholders and may be used as a practical tool for managing in-office air pollution by ranking the office index relative to the index distribution of the U.S. stock of office buildings. The last important characteristic of IAPI is that it relates well with symptoms of office occupants. ${ }^{1}$

These indices are air pollution/quality indices. The objective of this paper is to enlarge the scope of indoor indices to include environmental comfort variables and formulate, estimate, and test the Indoor Environmental Index (IEI). Aiming to better describe the in-office environment and to include all potential causes of observed occupant symptoms, this study modifies the structure used to calculate the IAPI and estimates a new index, the Indoor Discomfort Index (IDI). ${ }^{43}$ The IAPI is formulated using measured concentrations of formaldehyde (HCHO), TVOC, carbon monoxide $(\mathrm{CO})$, carbon dioxide $\left(\mathrm{CO}_{2}\right)$, particulate matter $\left(\mathrm{PM}_{10}\right.$, $\mathrm{PM}_{2.5}$ ), bacteria, and fungi; the IDI is formulated using measured levels of temperature and relative humidity (RH). The average of these two indices is the IEI, which is calculated in selected areas of 100 office buildings. Association of the IEI with health symptoms is investigated with the help of a symptom index, the Percent of Occupants with Two or more Persistent Symptoms (POPS2).

\section{METHODS}

\section{The Database}

Data from the BASE study ${ }^{42}$ are used in this study. The BASE study, conducted between 1994 and 1998, concurrently measured pollutant concentrations and identified officebuilding occupant symptoms using self-administered questionnaires, along with building characteristics, according to a standard protocol ${ }^{44}$ that was a result of discussions over a series of workshops with $\sim 40$ indoor air quality experts from across the United States. A total of 100 buildings were investigated from 10 predetermined geographical areas (climatic regions). Cities with a population of more than 100,000 were randomly chosen in each region. Buildings were chosen from a random sample drawn from telephone databases in each city. The buildings were randomly selected without regard to IAQ complaints. Characterization of the buildings included environmental measurements, occupant questionnaire, heating, ventilation and air conditioning (HVAC) system, and other aspects of the building structure. Environmental measurements and administration of the occupant questionnaire were conducted in a representative space within the building. The test space was to be occupied by at least 50 full-time employees residing on no more than three floors (all were administered the questionnaire) and served by no more than two air-handling units. Environmental 
measurements included temperature, $\mathrm{RH}, \mathrm{CO}, \mathrm{CO}_{2}$, bioaerosol (bacteria, fungi), $\mathrm{PM}_{10}, \mathrm{PM}_{2.5}$, volatile organic compounds (VOCs), HCHO, and radon. Occupants were asked about workplace physical information, health and wellbeing, environmental conditions, and job characteristics. Additional information on the BASE study can be found in the literature. ${ }^{42,45,46}$

A brief description of environmental measurement and occupant questionnaire methods ${ }^{45}$ is provided here; detailed information can be found in the standard protocol. ${ }^{44}$ Samples for $\mathrm{HCHO}, \mathrm{PM}_{10}$, and bacteria and fungi were collected at each of the three indoor sampling sites. Duplicates of each of these samples were taken at one indoor site. Samplers for $\mathrm{PM}_{2.5}$ were located at only one indoor site. $\mathrm{PM}_{10}$ and $\mathrm{PM}_{2.5}$ samples were collected on filters and analyzed gravimetrically with a microbalance. Bacteria and fungi were collected on six-stage Anderson samplers. HCHO samples were collected on dinitrophenylhydrazine cartridges and analyzed by high-performance liquid chromatography (HPLC). VOCs were collected on Summa canisters and analyzed with gas chromatography (GC)-mass spectrometry (MS) using the standard TO-14 method. $\mathrm{CO}_{2}, \mathrm{CO}$, temperature, and $\mathrm{RH}$ were measured continuously starting in the afternoon and ending the next day in the evening at three indoor sites.

\section{The IEI}

The IEI is a composite index aggregated from the IAPI and the IDI. The IAPI and the IDI are combined using the arithmetic mean as the aggregation function (eq 1).
Calculation of the IEI is performed hierarchically from pollutant concentrations and comfort variable values through a tree structure (Figure 1).

$$
\mathrm{IEI}=\frac{(\mathrm{IAPI}+\mathrm{IDI})}{2}
$$

\section{The IAPI}

The following eight pollutants are included in the index formulation: bacteria, $\mathrm{CO}, \mathrm{CO}_{2}, \mathrm{HCHO}$, fungi, $\mathrm{PM}_{2.5}$, $\mathrm{PM}_{10}$, and TVOC. The IAPI formulated using this set of pollutant concentrations is the modified IAPI because the original index was formulated using radon instead of $\mathrm{CO}_{2}$. The change was thought necessary for two reasons: (1) $\mathrm{CO}_{2}$ levels relate to the ventilation rate of a building, and (2) radon concentrations do not relate with the shortterm, reversible symptoms investigated in this work. A linear function is used to calculate subindices. The IAPI is a composite index; subindices are aggregated using arithmetic means in conjunction with a tree-structured calculation method (Figure 1). The IAPI is calculated using the following model:

$$
\begin{aligned}
& I A P I=\frac{1}{I} \sum_{\mathrm{i}=1}^{\mathrm{I}} \frac{1}{J} \sum_{\mathrm{j}=1}^{\mathrm{J}} \frac{1}{K} \sum_{\mathrm{k}=1}^{\mathrm{K}} 10\left(1-\frac{C_{\mathrm{i}, \mathrm{j}, \mathrm{k}}{ }^{\max }-C_{\mathrm{i}, \mathrm{j}, \mathrm{k}}{ }^{\mathrm{obs}}}{C_{\mathrm{i}, \mathrm{j}, \mathrm{k}}{ }^{\max }-C_{\mathrm{i}, \mathrm{j}, \mathrm{k}}^{\min }}\left(\frac{C_{\mathrm{i}, \mathrm{j}, \mathrm{k}}^{\mathrm{dmc}}-C_{\mathrm{i}, \mathrm{j}, \mathrm{k}}{ }^{\text {obs }}}{C_{\mathrm{i}, \mathrm{j}, \mathrm{k}}{ }^{\mathrm{dmc}}}\right)\right) \\
& \text { for } C^{\max }>C^{\text {obs }} \text { and } C^{\text {dmc }}>C^{\text {obs }}>C^{\min }
\end{aligned}
$$

where $I$ is the number of level-3 groups, $I=2$; $J$ is the number of level-2 groups in each level-3 group, $J=2 ; K$ is
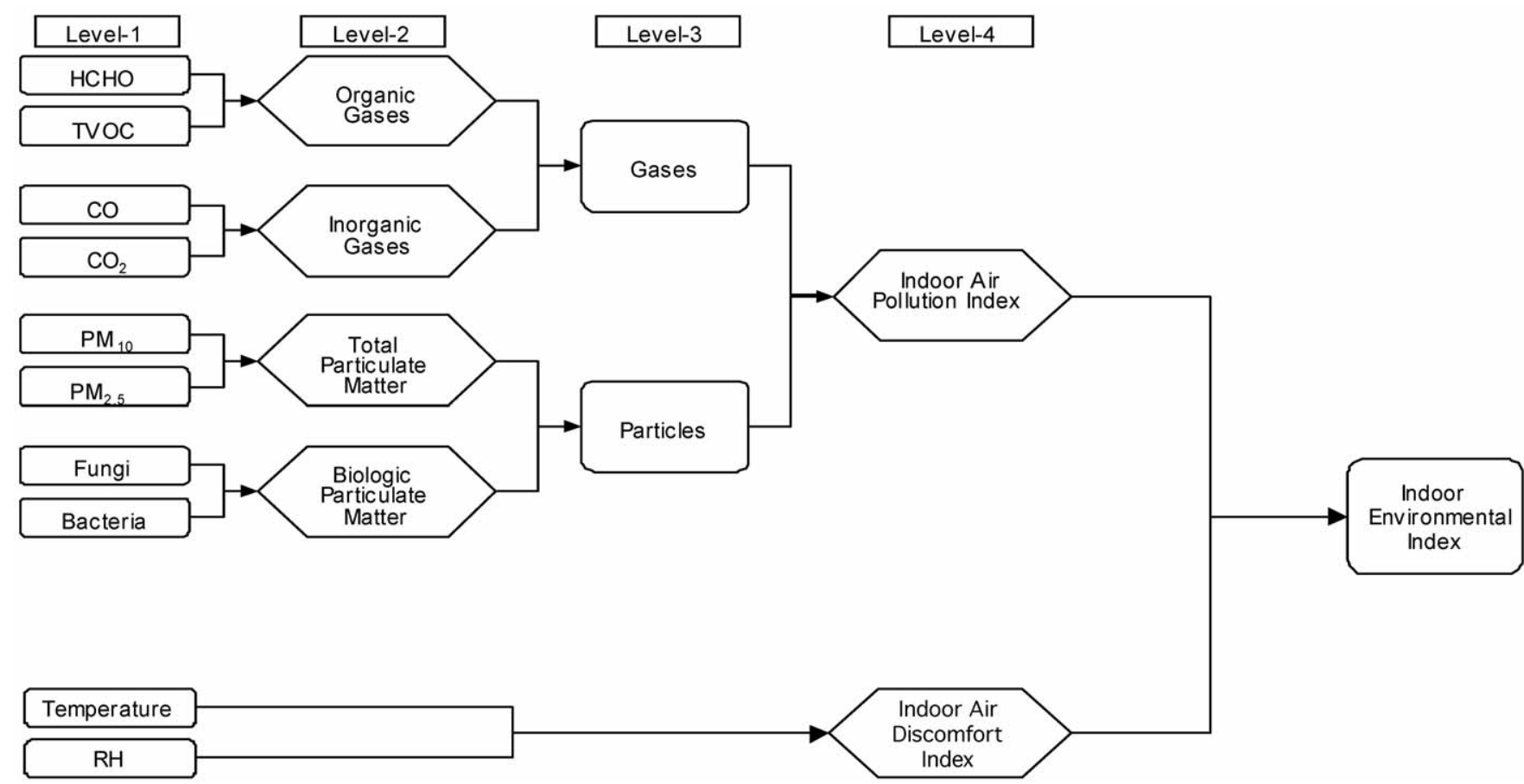

Figure 1. Tree structure for the IEI. 
the number of level-1 pollutant variables in each level-2 group, $K=2$; max is the maximum measured concentration; min is the minimum measured concentration; $d m c$ is the demarcation concentration; obs is the measured concentration in the subject building.

The range of pollutant concentrations from the BASE study, a demarcation concentration (a standard or guideline value), and measured concentrations in the subject building are used to estimate the IAPI of an office environment. The index is a unitless single number, between 0 (lowest pollution level or best indoor air quality) and 10 (highest pollution level or worst indoor air quality). Constraints for calculation of the IAPI include the following: (1) $C^{\text {obs }}=C^{\max }$ and $C^{\text {obs }}=C^{\mathrm{dmc}}$ when $C^{\max }$ is less than $C^{\text {obs }}$, (2) $C^{\text {obs }}=C^{\text {dmc }}$ when $C^{\text {dmc }}$ is less than $C^{\text {obs }}$ but $C^{\text {obs }}$ is less than or equal to $C^{\max }$, and (3) $C^{\text {obs }}=C^{\min }$ when $C^{\text {obs }}$ is less than $C^{\text {min }}$.

Demarcation values represent standards, guidelines, and suggestions of pollutant levels associated with health effects. Therefore, the weight of a pollutant into the IAPI estimations is determined by employing health-based demarcation values (Table 1) and is a function of occupant health effects, except for TVOC. Molhave ${ }^{31}$ suggests 200 $\mu \mathrm{g} / \mathrm{m}^{3}$ as the upper boundary of the comfort range for TVOC; Seifert 47 advocates $300 \mu \mathrm{g} / \mathrm{m}^{3}$ as a reasonably achievable level in residences. However, these concentrations are far less than the observed concentrations in office buildings. Therefore, a demarcation value was not included into the index for TVOC; that is, a unit value is assumed for the weight of TVOC, $\left(C^{\mathrm{dmc}}-C^{\mathrm{obs}}\right) / C^{\mathrm{dmc}}=1$. All relevant demarcation values used for the model formulation are obtained from the literature; they may change in the future as researchers continue investigating standards or guidelines for individual pollutants. The average of the measured concentrations at the three sampling sites for each pollutant in the subject building is used as the observed concentration, $C^{\text {obs }}$. Maximum and

Table 1. Demarcation values for pollutant variables.

\begin{tabular}{|c|c|c|}
\hline Pollutant & Demarcation & Source \\
\hline Bacteria & $500 \mathrm{cfu} / \mathrm{m}^{3}$ & European Collaborative Action50 \\
\hline $\mathrm{CO}$ & $10 \mathrm{mg} / \mathrm{m}^{3}$ & World Health Organization ${ }^{51}$ \\
\hline $\mathrm{CO}_{2}$ & 1000 ppm & ASHRAE Standard $62^{52}$ \\
\hline \multirow[t]{2}{*}{ Fungi } & $500 \mathrm{cfu} / \mathrm{m}^{3}$ & World Health Organization³ \\
\hline & & Health and Welfare Canada 54 \\
\hline $\mathrm{HCHO}$ & $60 \mu \mathrm{g} / \mathrm{m}^{3}$ & Health and Welfare Canada55 \\
\hline $\mathrm{PM}_{10}$ & $150 \mu \mathrm{g} / \mathrm{m}^{3}$ & EPA NAAQS56 \\
\hline \multirow[t]{2}{*}{$\mathrm{PM}_{2.5}$} & $40 \mu \mathrm{g} / \mathrm{m}^{3}$ & Health and Welfare Canada55 \\
\hline & & Norwegian Directorate of Health57 \\
\hline TVOC & NA & NA \\
\hline
\end{tabular}

Note: NAAQS: National Ambient Air Quality Standards; NA: not applicable. minimum concentration values for each pollutant were estimated from corresponding concentration distributions. A theoretical distribution was fitted to the measured concentrations of each pollutant obtained from the BASE database, and the fifth and ninety-fifth percentile values were assigned to use as $C^{\min }$ and $C^{\text {max }}$ in the index model. The following distributions were fitted to each pollutant's concentration data using Crystal Ball ${ }^{48}$ software: beta, exponential, extreme value, gamma, logistic, lognormal, normal, and Weibull. Parameters of the hypothesized distributions are estimated using the maximum likelihood estimators (MLEs) method. Goodness-of-fit tests-Chisquare, Kolmogorov-Smirnov, and Anderson-Darlingwere used to determine the best-fitting distribution.

\section{The IDI}

The IDI is estimated using two indoor comfort variables, temperature and $\mathrm{RH}$, with eq 3 . The absolute distance of the observed value to the defined optimum value $\left(22{ }^{\circ} \mathrm{C}\right.$ for temperature and $45 \%$ for $\mathrm{RH}$ ) relative to the preset comfort range $\left(3{ }^{\circ} \mathrm{C}\right.$ for temperature and $10 \%$ for $\mathrm{RH}$ either way from the optimum value) is used to estimate the IDI. The index is a unitless single number ranging from 0 to 10. High index values indicate high discomfort while low index values denote low discomfort. Constraints for calculation of the IDI include (1) $C A_{\mathrm{RH}, \mathrm{obs}}=$ 65 when $C A_{\mathrm{RH}, \mathrm{obs}} .>65$, (2) $C A_{\mathrm{RH}, \mathrm{obs}}=25$ when $C A_{\mathrm{RH}, \mathrm{obs}}$ $<25$, (3) $C A_{\mathrm{T}, \mathrm{obs}}=28$ when $C A_{\mathrm{T}, \mathrm{obs}} \cdot>28$, (4) $C A_{\mathrm{T}, \mathrm{obs}}=16$ when $C A_{\mathrm{T}, \mathrm{obs}}<16$.

$$
\text { IDI }=\frac{1}{L} \sum_{\mathrm{l}=1}^{\mathrm{L}} 10 \frac{\left|C A_{\mathrm{i}, \mathrm{opt}}-C A_{\mathrm{i}, \mathrm{obs}}\right|}{C A_{\mathrm{i}, \mathrm{ucl}}-C A_{\mathrm{i}, \mathrm{lcl}}}
$$

$$
\text { for } 25>C A^{\text {obs }}>65 \text { for } R H \text {, and } 28>C A^{\text {obs }}>16 \text { for } T
$$

where $C A$ is comfort agent, $L=2$; opt is optimum comfort agent value, $T_{\mathrm{opt}}=22{ }^{\circ} \mathrm{C}, R H_{\mathrm{opt}}=45 \% ; \mathrm{ucl}$ is upper comfort level, $T_{\mathrm{ucl}}=25{ }^{\circ} \mathrm{C}, R H_{\mathrm{ucl}}=55 \%$; lcl is lower comfort level, $T_{\mathrm{lcl}}=19{ }^{\circ} \mathrm{C}, R H_{\mathrm{lcl}}=35 \%$; and $o b s$ is measured comfort agent value in the subject building.

\section{Simulating the Indices}

Simulation of the index models was conducted using the Monte-Carlo method to estimate the distribution of the IEI for the U.S. office building stock. ${ }^{48}$ Probabilistic approximations were obtained through repetitive random calculation of the index equations. The simulation calculates each of the index value 10,000 times to form the probability distribution for the indices by sampling from the assigned distributions of the 10 input variables (pollutant concentrations and comfort variables) included in the model. The input variables are assumed to be independent 
of each other in the simulation. The validity of the assumption was investigated with a correlation matrix that tests the correlation coefficients of all pairs of pollutants used in the index. The only relatively high correlation value was that between $\mathrm{PM}_{10}$ and $\mathrm{PM}_{2.5}$, with a correlation coefficient of 0.82 . All other correlation coefficient values have $r$ values of less than 0.30. Therefore, a simulation was run accounting for the correlation between $\mathrm{PM}_{10}$ and $\mathrm{PM}_{2.5}$, so that the simulation could reflect real conditions of in-office environments to the extent possible.

\section{Occupant Symptoms and the Symptom Metric}

The questionnaire requests information about occupants' symptoms, their perceptions of their building's IAQ and work environment, and other stressors. The questionnaire was self-administered by occupants of the sampling space on Thursday of the sampling week, with steps taken to maintain confidentiality. The occupants were asked to return the questionnaires by that afternoon, which allowed for any follow-up collection on Friday. Occupants were asked about 19 symptoms: dry eyes, wheezing, headache, sore throat, fatigue, chest tightness, sinus infection, cough, tired eyes, tension, pain in back or shoulders, sneezing, difficulty concentrating, dizziness or light-headedness, feeling depressed, shortness of breath, nausea, and dry skin. The survey posed the following question to the occupants of the office area sampled in the performance of the study: During the past 4 weeks when you were at work, how often have you experienced each of the following symptoms while working in this building?
A. Not in the last 4 weeks.
B. 1-3 days in the last 4 weeks.
C. 1-3 days per week in the last 4 weeks.
D. Every or almost every workday.

In this study, occupants registering either C or D were considered to be experiencing symptoms persistently, and POPS2 was defined as a symptom metric, an indicator of a subject building's symptom status. POPS2 is the percent of occupants in the sampled area of the office building persistently registering two or more symptoms at least 1-3 days per week in the past 4 weeks.

\section{IEI Index-POPS2 Symptom Metric Relationships} Simple linear regression is used to correlate occupant symptoms and index values. Information from 71 out of the 100 buildings was used to formulate the index. Five buildings were excluded because statistical analyses indicated that these buildings were far removed from the remaining set of offices; data from the remaining 24 were used to verify the model capability to be used for application purposes. Two approaches were carried out to construct regression models. First, the index values were ranked in ascending order. Buildings were grouped by their index values using a grouping interval of index $=0.4$ (e.g., 0-0.4, 0.4-0.8, 0.8-1.2), forming 13 groups for the IEI. Arithmetic mean values for POPS2 and the indices were calculated for each group. Mean values were used in constructing a simple linear regression model. As in the first approach, the second approach ranks buildings in accordance with their IEI value, but this approach uses moving average to develop an index-POPS2 association. Moving average values for the IEI and corresponding moving averages for POPS2 were calculated using a gap width of 10 buildings. Coefficient of determination $\left(\mathrm{R}^{2}\right), p$ value for the $F$ statistic, and 95\% confidence intervals about the mean and individual responses were estimated and reported for each constructed regression.

\section{RESULTS AND CONCLUSIONS}

\section{Assumptions, Assertions, and Assessment}

Associations established use a correlative model and, as such, are applicable only to the data used for the formulation of the model. BASE is a national database of the environmental quality of office buildings. The selection of 100 office buildings is assumed to represent the U.S. office building population. Independently of whether measurements of three sites of a randomly selected area within each building characterize the environmental quality of the building, it is assumed that these measurements are an element of the environmental quality of the subject office population. The model also was verified by a randomly selected segment of the database that was not used for the development of the model.

The model is not applicable for other types of buildings, such as residences, schools, or hospitals. The model is a potential practical tool as formulated and has not been assessed in any other form. It also is presumed that inclusion of additional pollutants may or may not improve the association model, but such an addition may limit its potential for widespread use because measurement of a large number of pollutants is expensive. The index developed is a practical tool because it satisfies the three requirements of scientific and practical indices. In the balance of this document, the index is assessed initially by describing statistically the variables used and concluding with a section on a conceptual justification of the observed associations.

\section{Descriptive Statistics}

Central tendency and variability statistics for the input variables (pollutant variables and comfort variables) and the output variables (IEI, IAPI, and IDI) of the index model are presented in Tables 2 and 3, respectively. Fifth and ninety-fifth percentiles are specifically included 
Table 2. Descriptive statistics of input variables for the 100 office buildings.

\begin{tabular}{|c|c|c|c|c|c|c|c|c|c|c|}
\hline Statistic & $\begin{array}{c}\text { TVOC } \\
\left(\mu g / m^{3}\right)\end{array}$ & $\begin{array}{c}\text { НСНО } \\
\left(\mu g / m^{3}\right)\end{array}$ & $\begin{array}{c}\mathrm{CO}_{2} \\
\text { (ppm) }\end{array}$ & $\begin{array}{c}\mathrm{CO} \\
\left(\mathrm{mg} / \mathrm{m}^{3}\right)\end{array}$ & $\begin{array}{c}\mathrm{PM}_{2.5} \\
\left(\mu \mathrm{g} / \mathrm{m}^{3}\right)\end{array}$ & $\begin{array}{c}\mathrm{PM}_{10} \\
\left(\mu \mathrm{g} / \mathrm{m}^{3}\right)\end{array}$ & $\begin{array}{c}\text { Fungi } \\
\text { (cfu/m³) }\end{array}$ & $\begin{array}{l}\text { Bacteria } \\
\left(\mathrm{cfu} / \mathrm{m}^{3}\right)\end{array}$ & $\begin{array}{c}\text { Temp. } \\
\left({ }^{\circ} \mathrm{C}\right)\end{array}$ & $\begin{array}{l}\text { RH } \\
(\%)\end{array}$ \\
\hline Mean & 2168 & 15.7 & 573 & 0.136 & 8 & 12.6 & 62.9 & 46.1 & 20.7 & 44.9 \\
\hline Median & 1613 & 14.8 & 528 & 0.001 & 6.9 & 11.7 & 42.3 & 39.1 & 21.2 & 46 \\
\hline Standard deviation & 1664 & 8.3 & 127 & 0.34 & 3.8 & 6 & 68.3 & 26.1 & 2 & 15.8 \\
\hline Minimum & 159 & 3.4 & 381 & 0 & 2.4 & 3.6 & 3.5 & 0 & 15.7 & 13.2 \\
\hline Maximum & 9820 & 43.6 & 983 & 2.413 & 24.7 & 42.1 & 333.3 & 134.3 & 25.5 & 74.4 \\
\hline Distribution & LN & W & G & LN & LN & LN & LN & G & W & N \\
\hline Parameters & $\begin{array}{c}\mu=2178 \\
\sigma=1793 \\
-\end{array}$ & $\begin{aligned} L & =2.68 \\
S c & =14.46 \\
S h & =1.59\end{aligned}$ & $\begin{array}{c}L=355 \\
S c=78 \\
S h=2.81\end{array}$ & $\begin{array}{l}\mu=0.249 \\
\sigma=7.747\end{array}$ & $\begin{array}{l}\mu=7.98 \\
\sigma=3.87\end{array}$ & $\begin{array}{c}\mu=12.6 \\
\sigma=5.8\end{array}$ & $\begin{aligned} \mu & =66.8 \\
\sigma & =94.2 \\
S h & =2.42\end{aligned}$ & $\begin{array}{c}L=0 \\
S c=19.1 \\
S h=5.39\end{array}$ & $\begin{array}{l}L=11.2 \\
S C=10.3\end{array}$ & $\begin{array}{l}\mu=44.9 \\
\sigma=15.8\end{array}$ \\
\hline 5th percentile $e^{a}$ & 515 & 5 & 411 & 0.0001 & 3.4 & 5.5 & 6.9 & 10.2 & 17.5 & 19 \\
\hline 95th percentile ${ }^{\mathrm{a}}$ & 5490 & 32.2 & 824 & 0.599 & 15.3 & 23.5 & 216 & 103.2 & 24.2 & 70.8 \\
\hline
\end{tabular}

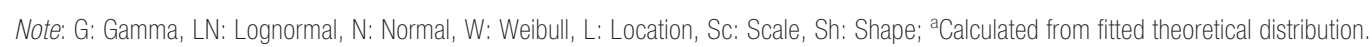

because these values are used as $C^{\max }$ and $C^{\min }$ in the estimation of the IAPI. Pollutant concentrations show large variations with right-skewed distributions. Five of eight of the pollutant concentration distributions are best described with the lognormal distribution, while concentrations of two pollutants $\left(\mathrm{CO}_{2}\right.$ and bacteria) are distributed in accordance with a gamma distribution, and one pollutant, $\mathrm{HCHO}$, has the Weibull distribution as the best-fitting distribution. Temperature and $\mathrm{RH}$ distributions are more symmetrical compared with pollutant concentration distributions, with Weibull and normal distributions, respectively. The IEI, IAPI, and IDI distributions estimated using the Monte-Carlo method are presented in Figure 2. Distribution of the IEI is best described by the Weibull distribution (location parameter $=0.8$, scale parameter $=3.5$, shape parameter $=3$ ), while the IAPI $($ Alpha $=8.67$, Beta $=17.78$, scale parameter $=10.4)$ and the IDI (Alpha $=2.23$, Beta $=3.33$, scale parameter $=$ 10.8 ) are best described with the beta distribution.

\section{Sensitivity Analysis}

The relative percentage of variance (RPV) in the IEI attributable to each input variable was calculated to estimate the relative importance of pollutant variables with respect to their effect on the IEI variation. The correlation coefficients for rank correlation between the IEI and each

Table 3. Descriptive statistics of output variables for the 100 buildings.

\begin{tabular}{lcccc}
\hline \hline Statistic $(\boldsymbol{n}=\mathbf{1 0 0})$ & POPS2 & IAPI & IDI & IEI \\
\hline Mean & 62.4 & 3.4 & 5.1 & 4.2 \\
Median & 62.1 & 3.3 & 5.1 & 3.9 \\
Standard deviation & 12.1 & 1.2 & 2.4 & 1.4 \\
Minimum & 27.3 & 0.5 & 0.2 & 0.7 \\
Maximum & 92.3 & 7.1 & 10 & 7.6 \\
\hline \hline
\end{tabular}

input variable were calculated. A higher correlation between an input variable and the output variable indicates a higher impact of that input variable on the output compared with input variables with lower correlation. RPV values were calculated as squared rank correlation coefficients normalized against 100\%. Table 4 lists RPV values and rank correlation coefficients for each input variable. Temperature has the greatest impact on the IEI distribution, but the other comfort agent, $\mathrm{RH}$, has the least impact on the distribution. The second largest correlation value is between IEI and $\mathrm{PM}\left(\mathrm{PM}_{10}\right.$ and $\left.\mathrm{PM}_{2.5}\right)$.

\section{Index Criterion I:}

\section{The IEI as a Communication Tool}

The IEI distribution for the U.S. office building stock was estimated using Monte-Carlo simulations (Figure 2). Median and 90th percentile IEI values are 3.9 and 5.3, respectively. The cumulative IEI distribution may be used as a communication tool because it characterizes the status of the indoor air environment of an office building relative to that of the stock of office buildings in the United States. An office building with an IEI value of 6.4 has an environmental quality that is of greater concern than a building with an IEI equal to 4.5. More specifically, the percentile value of the distribution corresponding to a subject building's index value shows its ranking in the officebuilding population. A building index value of 4.5 declares that almost $70 \%$ of the office buildings in the United States have better environmental index values than the building with IEI $=4.5$. Thus, the use of IEI values ranks in-office environmental quality in the range of $0-10$, and the cumulative index distribution ranks the environmental quality of a specific building under investigation relative to the environmental quality of the office-building population. These rankings furnish indoor air specialists with two easy-to-understand tools and help 

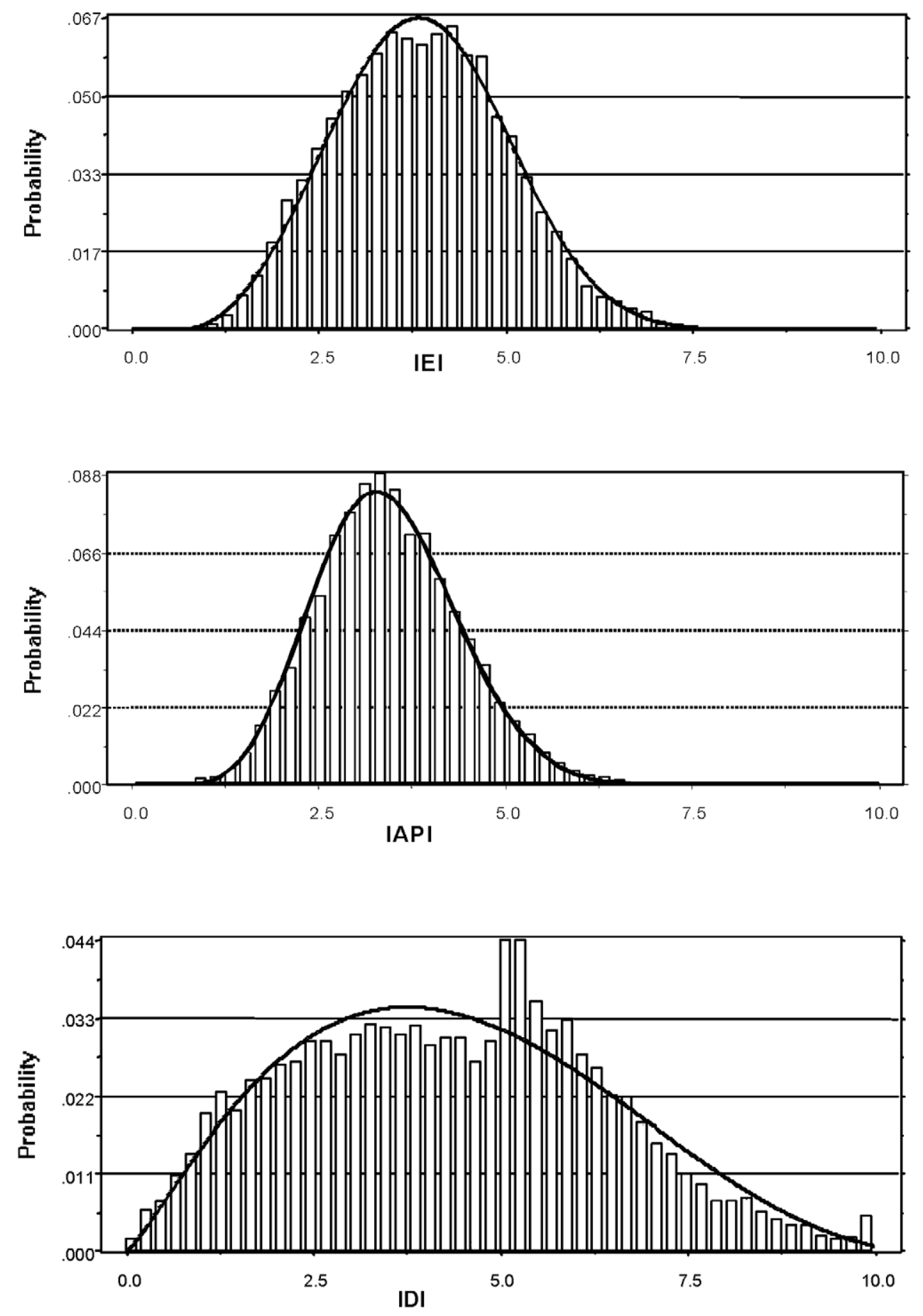

Figure 2. Distributions of the IEI, IAPI, and IDI estimated using Monte-Carlo simulation.

bridge the communication discord that exists among environmental quality specialists and the public, occupants, and decision-makers.

Criterion II:

The IEI-Occupant Symptom Associations

Two linear regression models were formulated to associate the IEI with POPS2 corresponding values in the total range of building IEI values. The symptom index, POPS2, was the dependent variable, with the IEI as the independent variable. Quantification of sensitivity of the IAPI to each of the pollutant variables showed that the index is not sensitive to small changes of concentration when only one pollutant is subject to variation. Sensitivity analysis and the desire to improve the strength of the association between the environmental and symptom indices led to grouping of buildings and to analysis using moving averages. The IEI model, constructed using group mean 
Table 4. Results of sensitivity analysis

\begin{tabular}{|c|c|c|c|c|c|c|}
\hline \multirow{2}{*}{$\begin{array}{l}\text { Target Index } \\
\text { Pollutant variable }\end{array}$} & \multicolumn{2}{|c|}{ IEI } & \multicolumn{2}{|c|}{ IAPI } & \multicolumn{2}{|c|}{ IDI } \\
\hline & & & & & & \\
\hline or index & $\mathrm{RCC}$ & RPV (\%) & RCC & RPV (\%) & $\mathrm{RCC}$ & RPV (\%) \\
\hline Temperature & - & - & - & - & -0.39 & 99.3 \\
\hline $\mathrm{RH}$ & - & - & - & - & 0 & 0.7 \\
\hline $\mathrm{PM}_{10}^{\mathrm{a}}$ & - & - & 0.61 & 30.3 & - & - \\
\hline $\mathrm{PM}_{2.5}{ }^{\mathrm{a}}$ & - & - & 0.6 & 29.9 & - & - \\
\hline $\mathrm{CO}_{2}$ & - & - & 0.33 & 9.6 & - & - \\
\hline $\mathrm{HCHO}$ & - & - & 0.36 & 10.8 & - & - \\
\hline Fungi & - & - & 0.34 & 9.8 & - & - \\
\hline TVOC & - & - & 0.3 & 7.6 & - & - \\
\hline Bacteria & - & - & 0.18 & 2.7 & - & - \\
\hline $\mathrm{CO}$ & - & - & 0.06 & 0.3 & - & - \\
\hline |AP| & 0.91 & 85.4 & - & - & - & - \\
\hline$|\mathrm{D}|$ & 0.38 & 14.6 & - & - & - & - \\
\hline
\end{tabular}

Note: RCC: Rank Correlation Coefficient; - : not used for the estimation of this index; ${ }^{\text {aCorrelated. }}$

values, has an $\mathrm{R}^{2}$ value of 0.67 and a $p$ value of 0.001 for the $F$ statistic (Model-1, Figure 3a). Although no general relationship as strong as the one constructed using group mean values is obtained, the coefficient of determination increases to 0.79 (Model-2, Figure 3b) for buildings that have IEI values greater than or equal to the median IEI value of 3.9 when moving average values are employed. Residual analysis indicates that neither of the models violates linear regression model assumptions.

Verification of the Index-Symptom Model. Focusing on the practical application of the index, we are not seeking to establish a cause and effect relationship; rather, we propose a potential practical environmental tool for building management. In the context of this paper, model verification denotes evaluation of a regression model with a 24-building database that was not used for the construction of the model. Note that buildings used for formulating models were randomly selected. The IEI, IAPI, IDI, and POPS2 values for the 24 buildings were calculated. The index value of each building was inserted in the regression model, and each building's symptom index (POPS2) value was estimated. The estimated-to-observed POPS2 ratio was used as the criterion to assess performance of the regression models. A ratio between 0.5 and 1.5 is considered to indicate acceptable model performance. Analysis indicates that estimations from the group mean model agree very well with the observed values (average ratio is 1.02 and standard deviation is 0.17 ). Only one of 24 buildings falls outside this criterion range. Residual analysis indicates that this building is an outlier. The remaining buildings display an excellent ratio in the range
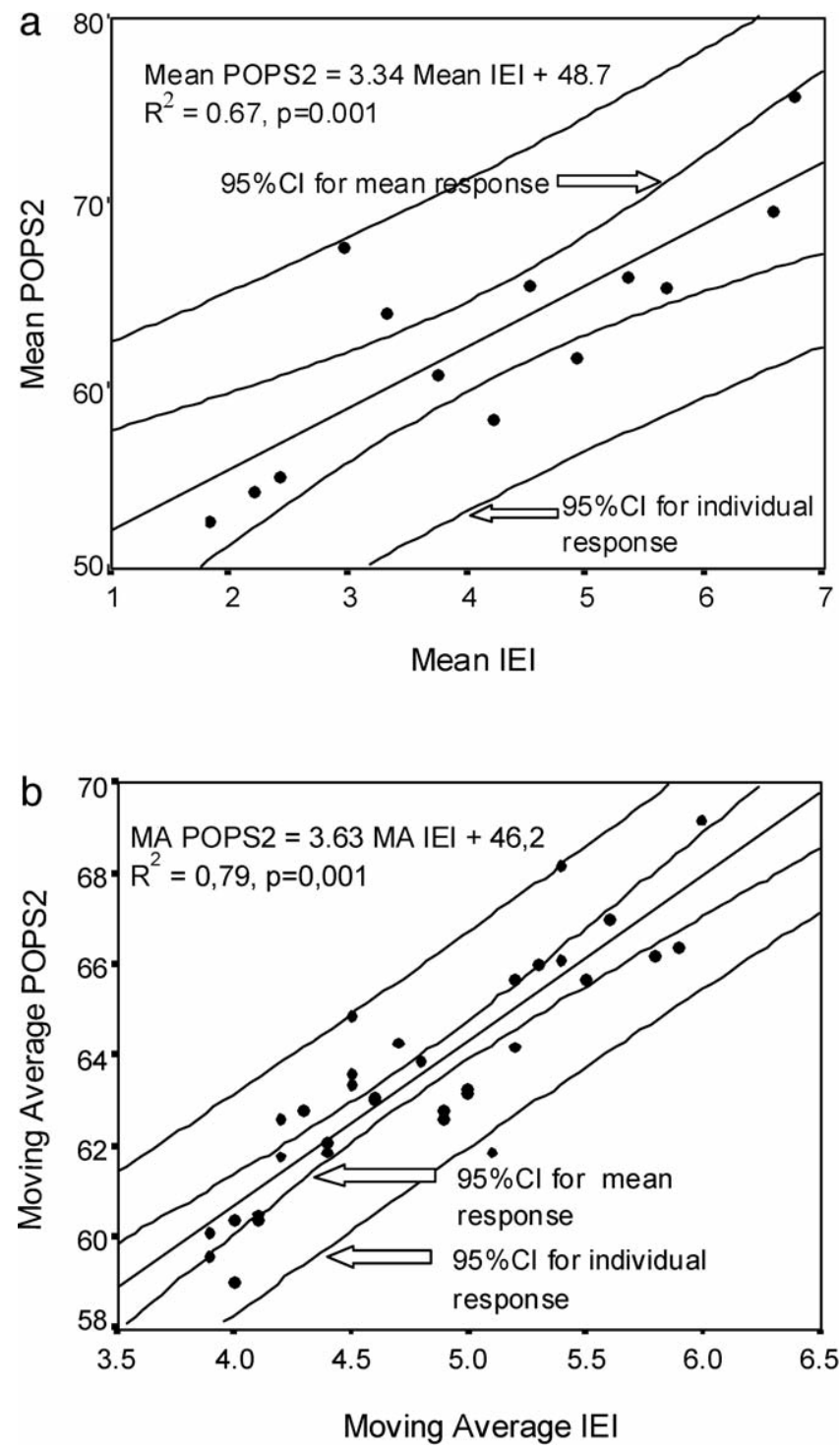

Figure 3. IEI-POPS2 simple linear regression models using (a) group mean values; (b) moving averages.

between 0.8 and 1.2. Performance of the moving average model is better compared with the group mean model, all estimated-to-observed ratio values are within the range of 0.75-1.25 (average ratio is 1.00 and standard deviation is 0.12$)$.

\section{Criterion III: The IEI as a Management Tool}

So far we have established that (1) the index is understood easily by all stakeholders of indoor environmental quality, and (2) the index is associated with occupant symptoms. In this section, we will elaborate on the process that employs the index as a management tool of indoor environmental quality. While similar arguments have been made for the IAPI, ${ }^{1}$ this section focuses on the IEI index.

Because sampling of indoor air and comfort variables can be a very expensive and laborious task, building managers frequently seek alternatives to sampling as the first 
step in the indoor environmental assessment process. The IEI index becomes a management tool because it may be estimated inexpensively, communicated easily, and associated well with occupant symptoms; these are advantages over measured individual pollutant concentrations that are expensive to measure, difficult to interpret and communicate, and do not associate with observed occupant symptoms. Because the association between the IEI and the occupant symptom POPS2 is given by simple linear regression, the dependent independent variables are reversed without losing any of the strength of the association. The following regression models have been constructed between POPS2 and IEI.

$$
\begin{gathered}
\text { IEI }=0.30 \text { POPS } 2-14.6 \\
\text { IEI }=0.28 \text { POPS } 2-12.7 \text { for POPS } 2 \geq 60 \%
\end{gathered}
$$

These models may be used for estimating the IEI index using the easy-to-obtain POPS2 index and for determining whether an intervention is required to improve the in-office environmental quality. The second model estimates higher levels of the IEI independently for the range of all possible IEI values. It leads to conservative IEI estimations; thus, for the practical purpose of determining whether a remediation intervention is required (see section on the conceptual model), the use of eq 5 is recommended.

While this procedure clearly reverses the dependent and independent variables in the regression models, it does not affect the strength of the relationships between the two variables because the models used are simple linear models. The reversal is thought tp be necessary because it is easier and less expensive to survey the occupants, calculate the POPS2 index, and use the equations to estimate the IEI of a building under investigation than it is to design and sample the environmental quality of a building and then estimate its IEI.

An indoor environmental quality study of an office begins when a building manager employs the BASE occupant symptom survey and estimates the building's IEI value using eq 5 . This value then is ranked relative to the cumulative IEI distribution. This constitutes the essence of the index as a management tool because the distribution enables the manager to decide the next step to be implemented using the relative ranking of the building's indoor air pollution in the population of office buildings. In addition, managers can justify their actions to the occupants as well as to the owners.

If all stakeholders (building owners, building manager, and occupants) agree that a sampling survey is needed, it will be designed and carried out. The IEI values will be estimated using the index model (i.e., measured pollutant concentrations and comfort agent values, see eq 1). Given these measurements, sub-index and IEI values will be calculated, and the tree structure will be constructed. Then, the contribution of each variable to the index will be estimated by decomposing the IEI. Identifying the contributing variables would lead to the most effective control strategy.

An example of the index decomposition process is provided in Figure 4 for a randomly selected building. Comparing the IAPI with the IDI contributions reveals that the larger portion of the IEI magnitude is because of air pollution (71\%) rather than comfort (29\%). The comparison of level-4 indices of gases and particles (5 vs. 7.7) and percent contributions to the higher-level index (39 vs. $61 \%$ ) show that particles contribute more to the IAPI but the contribution of gases should not be neglected. The contribution of an intermediate sub-level index to the IAPI is the proportion of the sub-level intermediate index value in the sum of the index values of all groups in that sub-level.

Comparison of level-2 intermediate indices for gases shows that inorganic pollutants (21\%) and organic pollutants (19\%) have a comparable contribution to the IAPI. Comparison of level-2 intermediate indices for particles produces a similar result: total (32\%) and biological (29\%) particles. Formaldehyde (14\%) and $\mathrm{CO}_{2}(17 \%)$ are the major contributing gaseous pollutants. Total contribution from the TVOC and CO is a mere $8 \%$. The contribution of $\mathrm{PM}_{2.5}$ and $\mathrm{PM}_{10}$ accounts for $\sim 32 \%$ to the IAPI. In addition, fungus is the last major contributing pollutant with $20 \%$.

It is concluded that the building has a problem associated with PM. Indoor sources such as smoking or outdoor penetration and an inefficient filtering system may be some of the causes of this source of elevated IAPI and, therefore, IEI values. The problem with fungi in the building may point to RH. For this example building, the contribution of RH to IDI (88\%) is much larger than that of temperature (12\%). Other than particles, formaldehyde and $\mathrm{CO}_{2}$ seem to be of concern; they are the next highest contributors to the index. This analysis suggests that there may be a problem with the ventilation system performance of the example building, which seems to fail to dilute indoor generated agents or capture those that are infiltrated from outdoors. It appears that indoor sources include high occupant density and moisture that emit $\mathrm{CO}_{2}$ and fungi, respectively, indoors. Given that smoking is not allowed in this building, the source of PM is likely to be the outdoors. These sources and the apparent or potential inability of the ventilation system to dilute indoor-generated pollutants and to filter out PM are responsible for the occupant symptoms. 


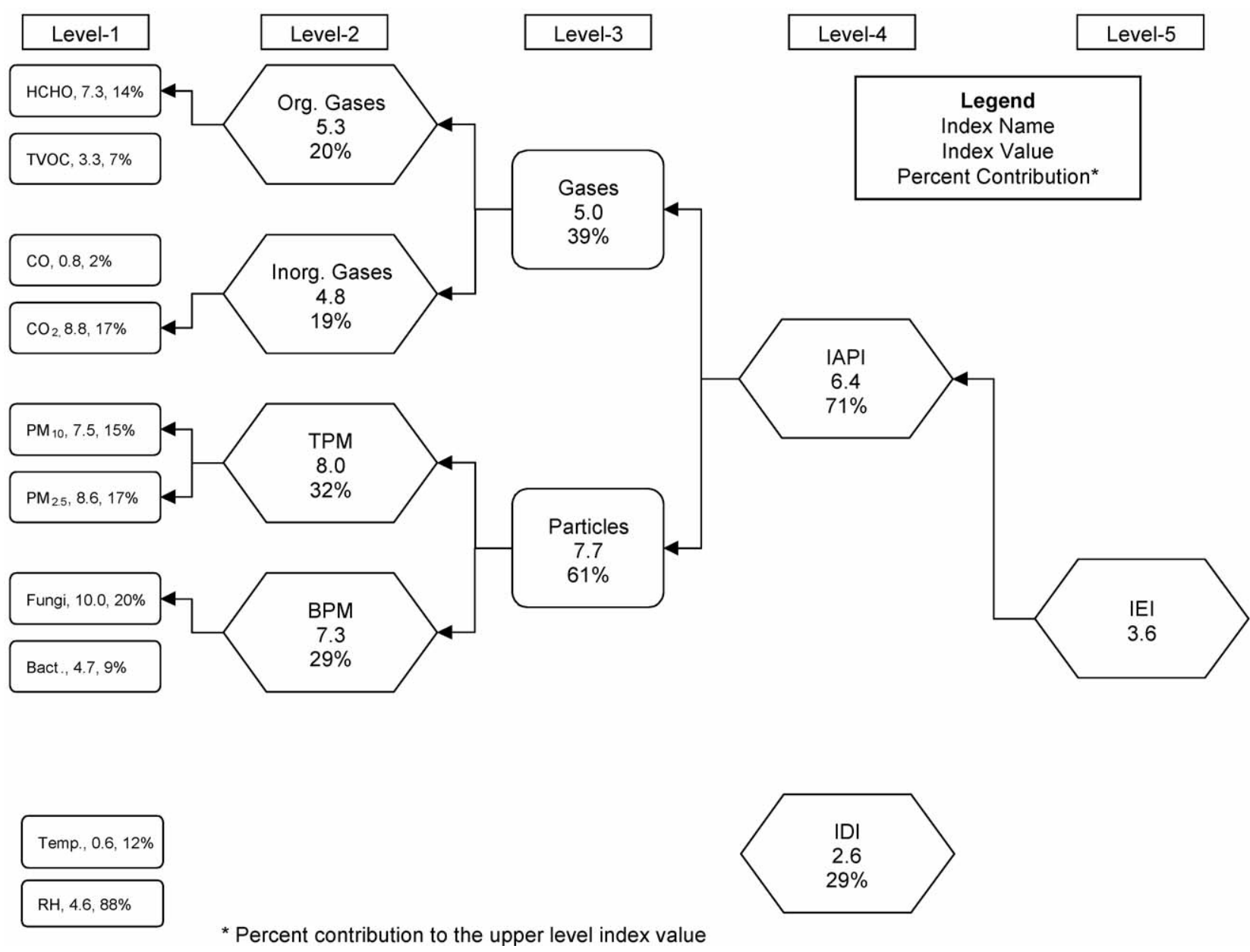

Figure 4. An example for the use of the IEl as a management tool.

The IEQ manager now has information on what potential sources and variables to concentrate on for an IEQ improvement strategy, if a decision is made that improvement is necessary. Note that the building manager can communicate with occupants easily by indicating that the present state of the building has a less than mean/ median index value and that only $<45 \%$ of similar buildings have lower values of IEI. The manager can further state that, although there does not seem to be a general problem with indoor air environment, there may be a need to reduce particle, formaldehyde, and $\mathrm{CO}_{2}$ levels. If remedial steps were to be taken, attention should be paid to performance of the ventilation system. A 50\% reduction in concentrations of these pollutants will take the IEI value down to 2.9 ; that is, only $\sim 20 \%$ of office buildings have lower IEI values.

\section{The Conceptual Model}

One of the objectives of this study is to formulate a conceptual model explaining the association of the index and the occupant symptoms. The relationship holds true over the total IEI range. Yet to formulate a mechanistic model, the IEI Office building values will be divided into three categories: (1) IEI values of less than 3.6; (2) $3.6<$ IEI values $<6$; and (3) IEI values $>6$. The number of buildings in each category is given in Table 5 . Thus, $\sim 30 \%$ of the buildings used for model formulation are assigned in the first category, a bit more than $60 \%$ in the second category, and the rest in the third category.

Constructed models and $\mathrm{R}^{2}$ values are shown in Table 6 . The relationship between the mean IEI and mean POPS2 is strong, as is the relationship between the moving average (MA) IEI and MA POPS2 for buildings with IEI <3.6. Estimated (using group means)-to-observed POPS2 ratio values are within the 0.7-1.2 range except for one building with a ratio of 1.5 (Avg. $=1.00$, Std. Dev. $=0.22$ ). Estimated (using moving averages) versus observed POPS2 regression has an $\mathrm{R}^{2}$ value of 0.39 for buildings with an IEI $<3.6$.

Although the relationships appear to be moderately strong and indicate that the moving average model predicts the observed values of office buildings not used to formulate the model relatively well, it is concluded that the $\mathrm{R}^{2}$ values are not acceptable for predictions with practical value. Thus, the conceptual model of this study suggests that, in an office building with IEI value of less than 3.6 , office occupant symptoms are not likely to be 
associated with in-office pollution. Consequently, it is recommended that the manager must seek other sources for the registered complaints.

The models for IEI in the range between 3.6 and 6 are discussed next. The first model is the mean IEI versus the mean POPS2 model; the second model relates the MA of IEI with MA of POPS2 (Table 6). Both of the models, associating IEI with POPS2 in the range between 3.6 and 6 , relate the two variables strongly, and the models are verified by the criteria set for this study. Estimated-toobserved POPS2 ratios are in the range of 0.75 and 1.2 for the mean IEI versus the mean POPS2 model (Avg. $=0.98$, Std. Dev. $=0.14$ ). Estimated (using moving averages) versus observed POPS2 regression has an $\mathrm{R}^{2}$ value of 0.66 for buildings with IEI value between 3.6 and 6. Consequently, the conceptual model suggests that the association between IEI and POPS2 can be used as a management tool for indoor air pollution studies and intervention designs.

The BASE database contains only eight office buildings with an IEI value greater than six-four buildings used and four buildings not used to formulate the models. Consequently, such office buildings are unusual. It is likely that indoor air pollution contributes to occupant complaints and, as such, it is recommend that in-depth indoor air pollution sampling and interpretation investigations must be performed.

Because two models, eqs 4 and 5, have been developed, one must be selected for estimating the IEI value of a building under investigation. The second model, eq 5 , is recommended because it leads to higher values of the IEI and, consequently, it affords greater protection of office building occupants, which is the main objective of any indoor environmental study.

In conclusion, the use of eq 5 along with information from the questionnaire is recommended to estimate the IEI of an office building under examination. If the IEI value is less than 3.6, no further action is suggested because the models constructed are unable to relate air pollution with occupant symptoms, and reduction of indoor air pollution or comfort conditions is not likely to reduce occupant symptoms. If the IEI value is higher than 3.6 but less than 6, further examination is suggested in accordance with the approach found in the section discussing

Table 5. Number of buildings used for the conceptual model.

\begin{tabular}{lcc}
\hline \hline Category & $\begin{array}{c}\text { Number of Buildings Used } \\
\text { for Model Development }\end{array}$ & $\begin{array}{c}\text { Number of Buildings Used } \\
\text { for Model Verification }\end{array}$ \\
\hline$|E|<3.6$ & 22 & 9 \\
$3.6 \leq|E| \leq 6$ & 45 & 11 \\
$|E|>6$ & 4 & 4 \\
\hline \hline
\end{tabular}

Table 6. Simple linear regression models constructed for the conceptual model.

\begin{tabular}{lcll}
\hline \hline $\begin{array}{l}\text { IEI } \\
\text { Range }\end{array}$ & $\begin{array}{c}\text { No. of } \\
\text { Data Points }\end{array}$ & Simple Linear Regression Model & $\mathbf{R}^{\mathbf{2}}$ \\
\hline$<3.6$ & 5 & Mean POPS2 $=8.63$ Mean IEI +35.6 & 0.93 \\
$<3.6$ & 27 & MA POPS2 $=8.39$ MA IEI +36.3 & 0.85 \\
$3.6-6$ & 6 & Mean POPS2 $=4.96$ Mean IEI +39.7 & 0.58 \\
$3.6-6$ & 42 & MA POPS2 $=5.84$ MA IEI +36.1 & 0.76 \\
\hline \hline
\end{tabular}

IEI as a management tool. If the estimated IEI value is greater than 6 , then the building must undergo a detailed indoor air pollution investigation because occupant complaints are likely to be related to and possibly caused by indoor environmental conditions.

\section{ACKNOWLEDGMENTS}

The financial support provided by the Phillip Morris External Research Program through a research contract with Total Exposure Technologies, Inc., is gratefully appreciated.

\section{REFERENCES}

1. Sofuoglu, S.C.; Moschandreas, D.J. The Link between Symptoms of Office Building Occupants and In-Office Air Pollution: The Indoor Air Pollution Index; Indoor Air 2003, 13, 332-343.

2. Sekhar, S.C.; Tham, K.W.; Cheong, D.; Wong, N.H. A Study of Indoor Air Pollutant Standard Index (IPSI) and Building Symptom Index (BSI). In Proceedings of Healthy Buildings, Espoo, Finland, 2000; Vol 1, pp 145-150.

3. Jokl, M.V. New Units for Indoor Air Quality: Decicarbdiox and Decitvoc; Int. J. Biometeorol. 1998, 42, 93-111.

4. Lahallec, C. An Air Quality Index in the CLIM2000 Software. In Proceedings of the Healthy Buildings, Milan, Italy, 1995; Vol 3, pp 17091713.

5. Molhave, L. Biomarkers and Other Substitute Measures in Indoor Air Sciences; Indoor Air 2003, 13, 369-370.

6. Wolkoff, P. Are We Ready for Indoor air Pollution Indices?; Indoor Air 2003, 13, 371-372.

7. Moschandreas, D.J.; Sofuoglu, S.C. Indices of Indoor Air Pollution Must Be Interpreted for What They Are and Not for What They Should Be; Indoor Air 2003, 13, 375-376.

8. Green, M.H. An Air Pollution Index Based on Sulfur Dioxide and Smoke Shade; J. Air. Pollut. Control Assoc. 1966, 11, 703-706.

9. Rich, T.A. Air Pollution Studies Aided by Overall Air Pollution Index; Environ. Sci. Tech. 1967, 1, 796-800.

10. MURC. MURC Index Tells Detroiters How Dirty Air Is; Air Eng. 1968, $10,28$.

11. Fensterstock, J.C.; Goodman, K.; Duggan, G.M.; Baker, W.S. The Development and Utilization of an Air Quality Index. In Proceedings of 62nd Annual Meeting of the APCA, New York, 1969; Paper 69-73.

12. Babcock, L.R. A Combined Pollution Index for Measurement of Total Air Pollution; J. Air Pollut. Control Assoc. 1970, 20, 653-659.

13. Shenfeld, L. Note on Ontario's Air Pollution Index and Alert System; J. Air Pollut. Control Assoc. 1970, 20, 622.

14. Thomas, W.A.; Babcock, L.R.; Shults, W.B. Oak Ridge Air Quality Index; Report No. ORNL-NSF-EP-8; Oak Ridge National Laboratory: Oak Ridge, TN, 1971.

15. Bisselle, C.C.; Lubore, S.H.; Pikul, R.P. National Environmental Indices: Air Quality and Outdoor Recreation; Report No. MTR-6159; MITRE Corporation: McLean, VA, 1972.

16. Miller, T.L. Short Time Averaging Relationships to Air Quality Standards (STARAQS) - A Predictive Air Quality Index Model for Use by Air Pollution Agencies. In Proceedings of 66th Annual Meeting of APCA, Chicago, IL, 1973; Paper 73-351.

17. Inhaber, H. A Set of Suggested Air Quality Indices for Canada; Atmos. Environ. 1974, 9, 353-364.

18. Thom, G.C.; Ott, W.R.A. Proposed Uniform Air Pollution Index; Atmos. Environ. 1976, 10, 261-264. 
19. Barbiroli, G.; Mazzaracchio, P.; Raggi, A.; Alliney, S.A. Proposal for a New Method to Develop Synthetic Quality Indices for Air and Water; J. Environ. Manage. 1992, 36, 237-252.

20. Swamee, P.K.; Tyagi, A. Formation of an Air Pollution Index; J. Air \& Waste Manage. Assoc. 1999, 49, 88-91.

21. Ferreira, F.; Tente, H.; Torres, P. Air Quality in Major Portuguese Urban Agglomerations; Water Air Soil Pollut. 2002, 2, 103-114.

22. Horton, R.K. An Index Number Rating System for Rating Water Quality; J. Water Pollut. Control Fed. 1965, 37, 300-306.

23. Brown, R.M.; McClelland, N.I.; Deininger, R.A.; Tozer, R.G.A. Water Quality Index-Do We Dare?; Water Sewage Works 1970, 117, 339 343.

24. Prati, L.; Pavanello, R.; Pesarin, F. Assessment of Surface Water Quality by a Single Index of Pollution; Water Res. 1971, 5, 741-751.

25. Dinius, S.H. Social Accounting System for Evaluating Water Resources; Water Resources Res. 1972, 8, 1159-1177.

26. Walski, T.M.; Parker, F.L. Consumers Water Quality Index; J. Environ. Engin. Div. 1974, 100, 593-611.

27. Melloul, A.J.; Collin, M.A. Proposed Index for Aquifer Water Quality Assessment: The Case of Israel's Sharon Region; J. Environ. Manage. 1998, 54, 131-142.

28. Hammond, A.; Adriaanse, A.; Rodenburg, E.; Bryant, D.; Woodward, R. Environmental Indicators; World Resources Institute: Washington, DC, 1995.

29. Molhave, L.; Clausen, G. The Use of TVOC as an Indicator in IAQ Investigations. In Proceedings of Indoor Air, Nagoya, Japan, 1996; Vol 2, pp 37-48.

30. Andersson, K.; Bakke, J.V.; Bjorseth, O.; Bornehag, C.-G.; Clause, G.; Hongslo, J.K.; Kjellman, M.; Kjærgaard, S.; Levy, F.; Molhave, L.; et al. TVOC and Health in Non-Industrial Indoor Environments; Indoor Air 1997, 7, 78-91.

31. Molhave, L. Volatile Organic Compounds, Indoor Air Quality and Health. In Proceedings of Indoor Air, Ottawa, Canada, 1990, Vol 5; pp 15-33.

32. Jokl, M.V.; Leslie, G.B.; Levy, L.S. New Approaches for Determining Ventilation Rates: The Role of Sensory Perception; Indoor. Environ. 1993, 2, 143-148.

33. Parine, N. The Use of Odour in Setting Ventilation Rates; Indoor Environ 1994, 3, 87-95.

34. Fanger, P.O. Introduction of the Olf and the Decipol Units to Quantify Air Pollution Perceived by Humans Indoor and Outdoors; Energy Buildings 1988, 12, 1-6.

35. Fanger, P.O. The Olf and Decipol; ASHRAE J. 1988, 29, 35-38.

36. Guidelines for Ventilation Requirements in Buildings; Report No. 11; EUR 14449 EN; Commission of European Communities: Luxembourg, 1992.

37. Shi, M.H.; Tao, A.R. Investigation of the Comfort Evaluation Index CPD of Indoor Environments. In Proceedings of Indoor Air, Nagoya, Japan, 1996; Vol 1, 423-428.

38. Oseland, N.A.; Aizlewood, C.E.; Raw, G.J. The New Units of Perceived Air Quality: Where Are We Now? In Proceedings of Healthy Buildings, Budapest, Hungary, 1994; Vol 1, pp 513-518.

39. Hunt, W.F., Jr.; Ott, W.R.; Moran, J.; Smith, R.; Thom, G.; Berg, N. Korb, B. Guideline for Public Reporting of Daily Air Quality-Pollutant Standards Index (PSI); EPA-450/2-76-013; U.S. Environmental Protection Agency: Research Triangle Park, NC, 1976.

40. Moschandreas, D.J.; Sofuoglu, S.C. The Indoor Air Pollution Index. In Proceedings of Indoor Air, Edinburgh, Scotland, 1999; Vol 2, pp 261-266.

41. Moschandreas, D.J.; Sofuoglu, S.C. A Composite Index for Indoor Air Pollution. In Proceedings of Healthy Buildings, Espoo, Finland, 2000; Vol 3 , pp 549-554

42. Womble, S.E.; Girman, J.R.; Ronca, E.L.; Axelrad, R.; Brightman, H.S.; McCarthy, J.F. Developing Information on Buildings and Indoor Air
Quality (BASE '94): Part I-Study Design, Building Selection, and Building Descriptions. In Proceedings of Healthy Buildings, Milan, Italy, 1995; Vol 3, pp 1305-1310.

43. Moschandreas, D.J.; Sofuoglu, S.C. The Indoor Environmental Index and Its Relationship with Occupant Symptoms. In Proceedings of Indoor Air, Monterey, CA, 2002; Vol 4, pp 94-99.

44. A Standardized EPA Protocol for Characterizing Indoor Air in Large Office Buildings; U.S. Environmental Protection Agency: Washington, DC, 1994.

45. Girman, J.R.; Womble, S.E.; Ronca, E.L. Developing Information on Buildings and Indoor Air Quality (BASE '94): Part II-Environmental Pollutant Measurements and Occupant Perceptions. In Proceedings of Healthy Buildings, Milan, Italy, 1995; Vol 3, pp 1311-1316.

46. Indoor Air Quality in Large Buildings; U.S. Environmental Protection Agency: Washington, DC. Available at: http://www.epa.gov/iaq/ largebldgs/base_page.htm. Accessed 2001.

47. Seifert, B. Regulating Indoor Air. In Proceedings of Indoor Air, Berlin, Germany, 1990; Vol 5, pp 35-49.

48. Crystal Ball v. 4; Decisioneering Inc.: Denver, CO, 1998.

49. Guiding Principles for Monte Carlo Analysis; Risk Assessment Forum; U.S. Environmental Protection Agency: Washington, DC, 1997.

50. European Collaborative Action. Indoor Air Quality and Its Impact on Man. In Biological Particles in Indoor Environments; Report No. 12; Office for Official Publications of the European Communities: Luxembourg, 1993.

51. Guidelines for Air Quality; World Health Organization: Geneva, Switzerland, 2000.

52. Standard 62-1989R Ventilation for Acceptable Indoor Air Quality; ASHRAE: Atlanta, GA, 1989.

53. Indoor Air Quality: Biological Contaminants; Regional Publication Series No. 31; World Health Organization: Copenhagen, Denmark, 1988.

54. Health and Welfare Canada. Indoor Air Quality in Office Buildings: A Technical Guide; Department of National Health and Welfare: Ottawa, Canada, 1993.

55. Health and Welfare Canada. Exposure Guidelines for Residential Indoor Air Quality; Department of National Health and Welfare: Ottawa, Canada, 1987.

56. National Ambient Air Quality Standards; Office of Air Quality Planning and Standards, U.S. Environmental Protection Agency: Washington, DC, 1997.

57. Norwegian Directorate of Health. Guidelines for Indoor Air Quality; In Indoor Air Quality: A Comprehensive Reference Book; Maroni, M., Seifert, B., Lindwall, T., Eds.; Elsevier: Amsterdam, Holland, 1995.

\section{About the Authors}

Demetrios J. Moschandreas is a professor of environmental engineering at Illinois Institute of Technology in Chicago, IL. Sait C. Sofuoglu is an assistant professor at Izmir Institute of Technology in Izmir, Turkey. Address correspondence to: Demetrios J. Moschandreas, Department of Chemical \& Environmental Engineering, Illinois Institute of Technology, 10 West $33^{\text {rd }}$ Street, Chicago, IL, 60616; phone: 312-5673532; fax: 312-567-8874; e-mail: djm@iit.edu. 
Copyright of Journal of the Air \& Waste Management Association is the property of Air \& Waste Management Association and its content may not be copied or emailed to multiple sites or posted to a listserv without the copyright holder's express written permission. However, users may print, download, or email articles for individual use. 